\title{
Microsurgical Treatment of Parasagittal Meningiomas: Trying to Define the Prognostic Factors for Early Post-Operative Outcome at Benha Neurosurgery Department
}

\author{
MOATAZ A. ELAWADY, M.D. and MOHAMED E. ELHAWARY, M.D. \\ The Department of Neurosurgery, Faculty of Medicine, Benha University
}

\begin{abstract}
Background: Maximizing the removal of parasagittal meningiomas and reducing the incidence of surgical complications and tumor recurrence rates have always been the goal for neurosurgeons.

Aim of Study: We aim at trying to define the pre-operative and operative prognostic factors for early post-operative outcome at Benha Neurosurgery Department.

Patients and Methods: A number of 26 cases, 16 females and 10 males with age ranging between 35 and 65 years have parasagittal meningiomas operated between 2010 and 2018 at the Benha Neurosurgery Department and were retrospectively reviewed.

Results: Nine patients (34.6\%) showed deteriorated motor function. Seven of them (26.9\%) also showed deteriorated conscious level.

Conclusions: The following factors are associated with good early post-operative outcome: Middle age, no preoperative peritumoral edema and grade I or II resection.
\end{abstract}

Key Words: Parasagittal-Parafalcine-Prognostic factors.

\section{Introduction}

IN 1955, Hossly and Olivecrona classified parasagittal meningiomas into three groups based on their relation to the superior sagittal sinus: Anterior third located between crista galli and coronal suture, middle third located between coronal and lambdoid sutures, and posterior third located posterior to lambdoid suture [1]. Their incidence varies in the literature ranging from 17 to $27 \%$ of all intracranial tumors [2]

There are often no typical symptoms in the early stage of parasagittal meningiomas, and the tumor size is usually quite large by the time it is diagnosed. Maximizing the removal of tumors and

Correspondence to: Dr. Moataz A. El-Awady, The Department of Neurosurgery, Faculty of Medicine, Benha University reducing the incidence of surgical complications and tumor recurrence rates have always been the goal for neurosurgeons [3]

We aim at trying to define the pre-operative and operative prognostic factors for early post-operative outcome at Benha Neurosurgery Department.

\section{Patients and Methods}

Patients: A number of 26 cases, 16 females and 10 males with age ranging between 35 and 65 years have parasagittal meningiomas operated between 2010 and 2018 at the Benha Neurosurgery Department and were retrospectively reviewed. All cases proven pathologically to be meningioma. Family history was negative in allcases.

All patients underwent routine general and neurological examination, routine laboratory investigations and radiological assessment including Computed Tomography (CT) and Magnetic Resonance Imaging (MRI). Magnetic Resonance Venography (MRV) was done for all patients with significant oedema on MRI. Nine cases underwent a MRV examination, and four cases were discovered to have significant tumor stain in the venous phase.

\section{Methods:}

\section{Pre-operative intervention:}

For the cases who were shown (by MRI) to have significant peritumoral edema, $24 \mathrm{mg}$ of dexamethasone and $250 \mathrm{~mL}$ of $20 \%$ mannitol, Q12hQ8h was administered daily for 3 days prior to surgery [4].

\section{Surgical technique:}

All 26 cases were operated upon at the Neurosurgery Department of Benha University Hospitals 
by the authors. Supine position was used incases of unilateral lesions while semi-setting positionwas used in cases with bilateral lesion (dumbbellshaped)with different modification according to tumor size, aimingto bring the tumor at the top of the operative fieldwith adequate visualization and exposure. In unilateral cases, a U-shaped skin flap was based inferiorly, made wide enough to allow adequate exposure, while a bicoronal incision was made in cases with bilateralextension. Bone flap was designed to allow adequate tumor exposure; dural opening was performed to be beyondthe edges of the lesion and based on the Superior Sagital Sinus (SSS). After dural opening, careful dissection of dura from theunderlying cortex was done with a special attention topreserve all draining veins Fig. (2). Internal debulking of the lesion was started followed by dissection of the externalcapsule of the lesion from the surrounding brain tissue. Tumor parts attached to falx or SSS were the last portionto be removed, in cases where these parts were adherent to the falx cerebri or SSS without invading itscavity coagulation with bipolar was done Fig. (1). In cases withsinus invasion, resection of the tumor within the cavityand sinus wall was done; cases with dural invasion were subjected to duroplasty using fascia lata graft. Next day of surgery, radiological and neurological assessmentwas done. CT brain with contrast was thestandard radiological study used to evaluate extent of resectionin early post-op. period. The Simpson Grading System was used to describe theextent of resection [5] (Table 2).

Definition of outcome: The occurrence of disturbed conscious level or detiorated motor function compared to the pre-operative status in the first post-operative weak makes the early outcome bad, otherwise the outcome is considered good.

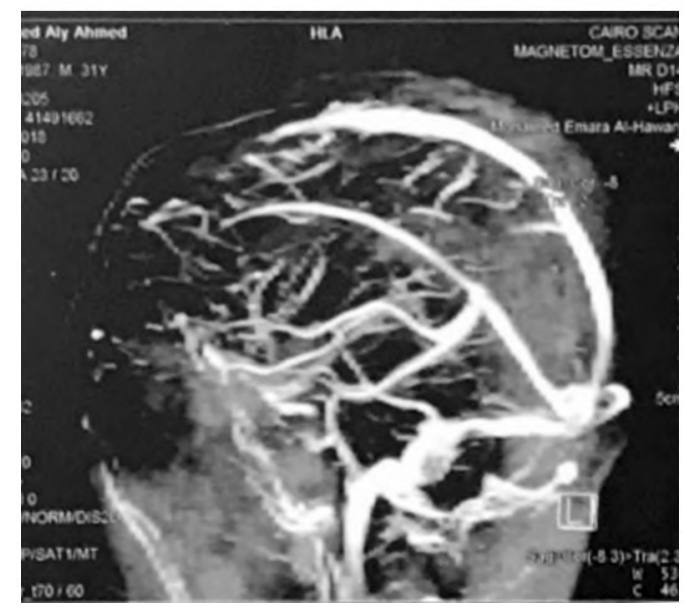

Fig. (1): DSA of a patient with parasagittal meningioma and oedema shows compression of the SSS by the tumor.

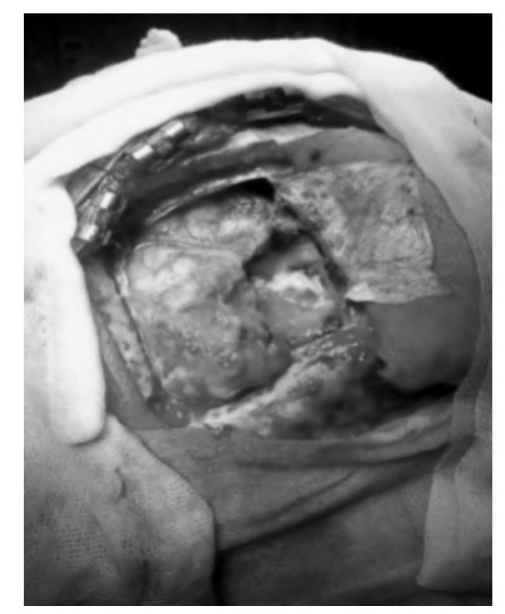

Fig. (2): Craniotomy and dural opening to expose an anterior parasagittal meningioma.

\section{Results}

The duration of the presenting symptoms varied between 2 and 24 months; presenting symptoms were seizures $69.2 \%$ (18 patients), headache $50 \%$ (13 patients), motor weakness $38.4 \%$ (10 cases), and disturbed conscious level $11.5 \%$ ( 3 cases).

In eleven patients the tumor was anterior to the coronal suture (A), in eight patients the tumor was posterior to the lambdoid suture $(\mathrm{P})$ while in seven patients it was between the coronal and lambdoid sutures (M). The tumor was unilateral in all but two patients. Multiple meningiomas was not found in any of our patients.

Twelve cases had an edema zone with a high $\mathrm{T} 2$ signal around the tumor, among them, there were six cases with widespread edema.

According to Simpson's classification (Table 3 ), Grade I resection was obtained in five patients while Grade II was obtained in 21 patients. Intraoperative sinus invasion was present in 4 patients; in these 4 cases, the tumors within the sinus cavity and the invaded sinus wall were excised and defect in sinus was closed. In 3 cases, we used direct sutures to close the gap, and gel foam was applied, while in the fourth case, an artificial dural graft was used to close the sinus defect. Histological types of the tumors were transitional in 10 patients, fibroblastic in 9 patients, meningiothelial in 5 patients and psamomatous in 2 patients (Table 3 ).

\section{Early post-operative outcome:}

Clinical outcome: Nine patients (34.6\%) showed deteriorated motor function. Seven of them (26.9\%) also showed deteriorated conscious level.

Radiological outcome: Post-operative radiological studies of the deteriorated patients revealed 
severe cerebral edema in 4 patients $(15.4 \%)$, while in the remaining 5 cases $(19.2 \%)$ there were no post-operative radiological changes that could be attributed to their deficits.

Table (1): Patient criteria.

\begin{tabular}{|c|c|c|c|c|c|c|c|}
\hline \multirow{2}{*}{$\frac{\text { Patient }}{1}$} & \multicolumn{2}{|c|}{ Sex Presenting symptoms } & Location & $\begin{array}{l}\text { Preopoedema } \\
\text { on MRI }\end{array}$ & $\begin{array}{l}\text { Simpson's } \\
\text { grading }\end{array}$ & \multirow{2}{*}{$\begin{array}{c}\begin{array}{c}\text { Histological } \\
\text { type }\end{array} \\
\text { Transitional }\end{array}$} & \multirow{2}{*}{$\begin{array}{l}\text { Outcome } \\
\text { Good }\end{array}$} \\
\hline & 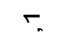 & Seiyures/he ache & $\checkmark$ & No & II & & \\
\hline 2 & $\tau$ & Seizures/weakss & $\sigma$ & No & II & Transitional & Good \\
\hline 3 & $\dot{t}$ & Seiyures/headach & $\pi$ & Yes & II & Fibroblastic & Good \\
\hline 4 & $r_{.}$ & Seizures/weakness & 0 & No & I & Fibroblastic & Good \\
\hline 5 & $r_{.}$ & Seiyures/headache & \# & Yes & II & Meningiothelial & Good \\
\hline 6 & $r_{.}$ & weakness & 幽 & Yes widespread & II & Transitional & $\mathrm{DCL}^{\wedge}$ weakness \\
\hline 7 & t & Seiyures/headache & \pm & No & II & Fibroblastic & $\mathrm{DCL}^{\wedge}$ weakness \\
\hline 8 & $\dot{\theta}$ & weakness & $0 \approx$ & Yes & I & Transitional & Increases weakness \\
\hline 9 & 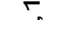 & Seiyures/headache & $\bar{\pi}$ & No & II & Psamomatous & Good \\
\hline 10 & \ulcorner & Seizures/weakness & 0 & Myes widespread & II & Fibroblastic & $\mathrm{DCL}^{\wedge}$ weakness \\
\hline 11 & $\tau_{.}$ & Seiyures/headache & $\sigma$ & $\mathrm{N}$ & II & Meningiothelia & Good \\
\hline 12 & $\dot{\jmath}$ & DCL & $\dot{\gamma}$ & Yes $\Sigma$ & $\mathrm{I}$ & Transitional & Good \\
\hline 13 & $r$ & DCL & $\sigma$ & No & II & Psamomatous & Good \\
\hline 14 & 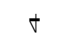 & weakness & 0 & Yes wide read & II & Transitional & $\mathrm{DCL}^{\wedge}$ weakness \\
\hline 15 & $\dot{\gamma}$ & Seiyures/headache & 0 & No & II & Fibroblastic & Good \\
\hline 16 & $r_{.}$ & Seiyures/headache & $\forall$ & No & II & Transitional & Good \\
\hline 17 & 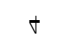 & Seiyures/headache & $\checkmark$ & No & $\Sigma$ & Meningiothelia & Good \\
\hline 18 & $r_{n}$ & Seizures/weakness & $\sigma$ & Yes widespread & II & Transitional & $\mathrm{DCL}^{\wedge}$ weakness \\
\hline 19 & $r_{.}$ & Seiyures/headache & $\pi$ & Yes & 每I & Fibroblastic & Good \\
\hline 20 & $\dot{t}$ & DCL & 0 & No & $\mathrm{II} \approx$ & Transitional & Good \\
\hline 21 & $r_{.}$ & Seiyures/headache & $\checkmark$ & Yes widespread & II & Fibroblastic & $\mathrm{DCL}^{\wedge}$ weakness \\
\hline 22 & $\dot{t}$ & weakness & $\sigma$ & No & I & Transitional & Good \\
\hline 23 & $r$ & weakness & 0 & Yes & II & Fibroblastic & Increases weakness \\
\hline 24 & t & Seizures/weakness & 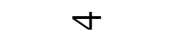 & Yes widespread & II & M雨ingiothelia & $\mathrm{DCL}^{\wedge}$ weakness \\
\hline 25 & $r_{.}$ & Seiyures/headache & م & No & II & Fibromlastic & Good \\
\hline 26 & $r$ & Seiyures/headache & $\sigma$ & No & II & Mening thelia & Good \\
\hline
\end{tabular}
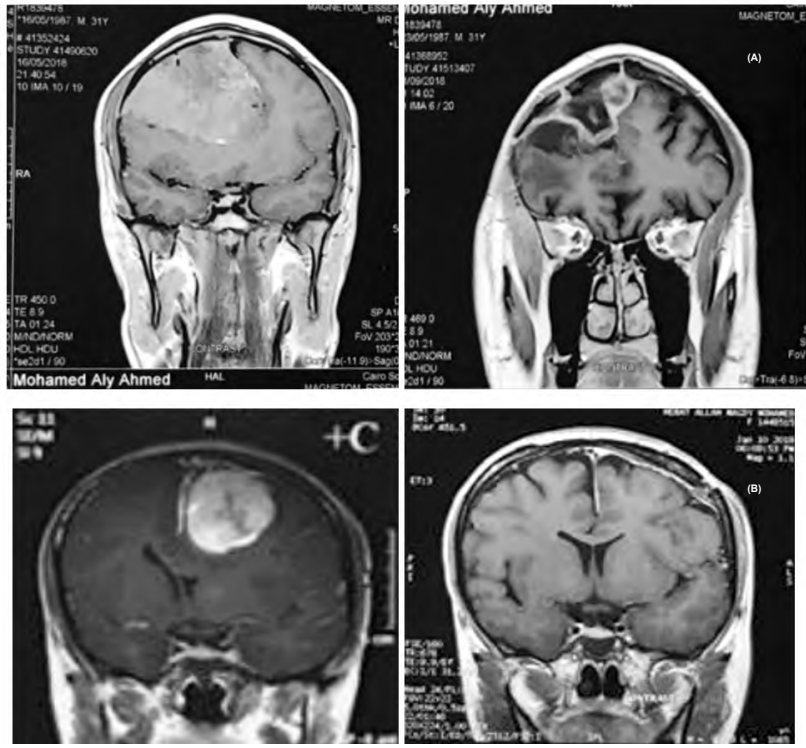

Fig. (3): (A) Case 1 pre-operative and post-operative (B) Case 2 pre-operative and post-operative of anterior parasagittal meningioma.

Table (2): Presenting symptoms in our patients.

\begin{tabular}{lc}
\hline Symptom & Number of patients $(\%)$ \\
\hline Seizures & $18(69.2)$ \\
Headache & $13(50)$ \\
Motor weakness & $10(38.4)$ \\
Disturbed conscious level & $3(11.5)$ \\
\hline
\end{tabular}

Table (3): Simpson's grading system.

\begin{tabular}{llc}
\hline Grade & Definition of corresponding resection & $\begin{array}{c}\text { Number of } \\
\text { patients }\end{array}$ \\
\hline I & $\begin{array}{l}\text { • Macroscopically complete resection } \\
\text { with excision of dural attachment and } \\
\text { abnormal bone. }\end{array}$ & 5 \\
& $\begin{array}{l}\text { - Macroscopically complete resection } \\
\text { with coagulation of dural attachment. }\end{array}$ & 21 \\
II $\quad$ Macroscopically complete resection & 0 \\
III $\quad \begin{array}{l}\text { without resection orcoagulation of } \\
\text { its attachment. }\end{array}$ & \\
IV & - Subtotal resection. & 0 \\
V & - Simple decompression of the tumor. & 0 \\
\hline
\end{tabular}

Table (4): Histopathological findings.

\begin{tabular}{|c|c|}
\hline Histopathological type & Number of patients (\%) \\
\hline Transitional & $10(38.4)$ \\
\hline Fibroblastic & $9 \quad(34.6)$ \\
\hline Meningiothelial & $5 \quad(19.2)$ \\
\hline Psamomatous & $2 \quad(7.7)$ \\
\hline
\end{tabular}




\section{Discussion}

Parasagittal meningiomas are usually associated with a higher incidence of motor power deterioration, either as a presenting symptom or a postoperative complication.

In a study done by Jian et al., [6], the incidence of motor weakness as a presenting symptom was $61 \%$. Shiro et al., [7] . Reported an incidence of $40 \%$ in their study, while incidence was $0 \%$ among lesions involving anterior and posterior third in the same study.

In our study, motor power deterioration was the presenting symptoms in 8 patients $(30.7 \%)$.

Regarding motor function, many authors documented poor results during early postoperative period. Akira et al., [8] reported an incidence around $50 \%$ in their study, where 8 patients out of 16 developed deterioration of motor power during early post-operative period, 6 cases showed hemiparesis, 5 of them had complete hemiplegia, and 2 cases showed monoparesis of the lower limb. Jian et al., [6] reported that $56 \%$ of their patients with pre-operative motor deficits developed worsening of motor function during early post-operative period (9 patients out of 16).

Venous system injury with subsequent cerebral edema, venous infarction, cortical injuries, and contusions areconsidered the main reasons for poor post-operative outcome regarding motor function [9-11]. However, in many cases, there is no pathology detected in post-operative radiological studies [12].Akira et al., [8] reported that in their series in spite of 8 patients out of 16 who developed deterioration of motor power during early post-operative period, only radiological studies were positive in 2 cases only (one case showed intracerebral hematoma and the other showed severe cerebral edema) [8]. In our study, post-operative radiological studies were negative in 5 cases with motor power deterioration, while 3 cases showed severe cerebral edema that required intensive medical therapy, including deep sedation and ventilation, and no surgical intervention was required for any deteriorated cases.

Sindou et al., have found that protection of central sulcus vein from injury and adopting some microsurgical techniques have resulted in absence of post-operative motor weakness in their patients

\section{Conclusions:}

Parasagittal meningioma is associated with a higher incidence of deterioration of conscious level or motor function during the early post-operative period. The following factors are associated with good early post-operative outcome: Middle age, no pre-operative peritumoral edema and grade I or II resection.

\section{References}

1- HOSSLY G.F. and OLIVECRONA H.: Report on 280 cases of verified parasagittal meningiomas. J. Neurosurg., 12: 614-25, 1955

2- YAMADA S., TAOKA T., NAKAGAWA I., et al.: A magnetic resonance imaging technique to evaluate tumorbrain adhesion in meningioma: Brain-surface motion imaging. World Neurosurg., 83: 102-7, 2015.

3- ELZARIEF A.A. and EBRAHIM M.F.: Long-term followup of motor function deterioration following microsurgical resection of middle third parasagittal and falx meningiomaThe Egyptian Journal of Neurology, Psychiatry and Neurosurgery, 54: 9, 2008.

4- NOWAK A., DZIEDZIC T., CZERNICKI T., KUNERT P. and MARCHEL A.: Surgical treatment of parasagittal and falcine meningiomas invading the superior sagittal sinus. Neurol. Neurochir. Pol., 48: 174-80, 2014.

5- SIMPSON D.: The recurrence of intracranial meningiomas after surgical treatment. J. Neurol. Neurosurg. Psychiatry., 20: 22-39, 1957.

6- JIAN, NA B., RUI-XUE X., RONG-YAO L., et al.: Microsurgical treatment of parasagittal meningioma in the central gyrus region. Oncol. Lett., 6: 781-4, 2013.

7- SHIRO K., THOMAS G. and JOHN M.: The surgical outcome of parasagittal and falxmeningioma in the era of microsurgery and computerized tomography. Bull Yamaguchi Med. Sch., 37 (3-4): 137-44, 1990.

8- AKIRA K. , HIDEKI M., KENICHI H., TOMOYUKI N and KENTARO W.: Surgical results of parasagittal and falx meningioma. Nagoya J. Med. Sci., 74: 211-6, 2012.

9- TOMASELLO F., CONTI A., CADRALI S. and ANGILERI F.F.: Venous preservation guided resection: A changing paradigm in parasagittal meningioma surgery. J. Neurosurg., 119 (1): 74-81, 2013.

10- BAZZAO A., FINOCCHI V. and ROMANO A.: Role of contrast-enhanced MR venography inthe pre-operative evaluation of parasagittal meningioma. Eur. Radiol., 15: 1790-5, 2005.

11- ELBORADY M. and KAMAL H.: Middle and posterior third parasagittal meningiomas: A preliminary study of twenty cases. Egy. J. of Neurosurg., 29 (2): 43-8, 2014.

12- SINDOU M.P. and ALVERNIA J.E.: Results of attempted radical tumor removal and venous repair in 100 consecutive meningiomas involving the major dural sinuses. J. Neurosurg., 105 (4): 514-25, 2006.

13- SINDOU M.: Meningiomas involving major dural sinuses Should we attempt at radical removal and venous repair? World Neurosurg., 81: 46-7, 2014. 


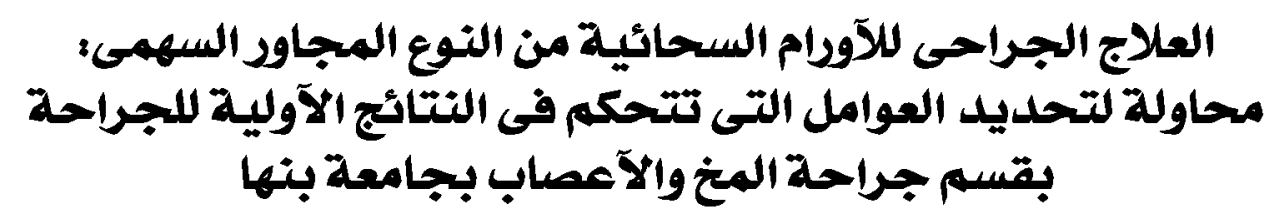

الخفلفية العلمية: إن تصسين نتائج إستئصال الآودام السحائية من النوع المجاور السهمى وتقليل مخاطر الجراحة وإحتماليات عودة الودم

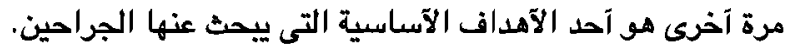

الهدف من الدراسدة: تحديد العوامل ما قبل الجراحة وآثناء الجراحة التى تتحكم فى النتائج الآولية لهذه الجراحات بقسمم جراحة المخ

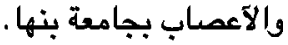

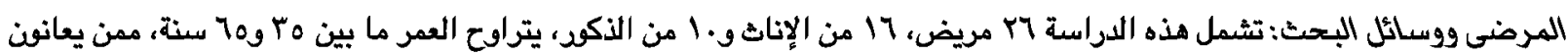

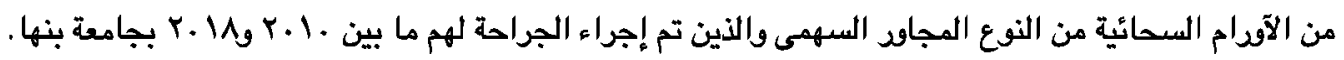

النتائج: 9 من المرضى حدث لهم تدهو بالحركة ما بعد الجراحة، وV منهم حدث لهم تدهود بلرجة الوعى آيضاً.

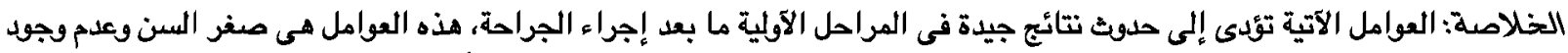

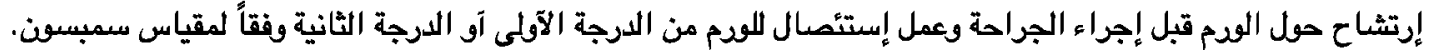

